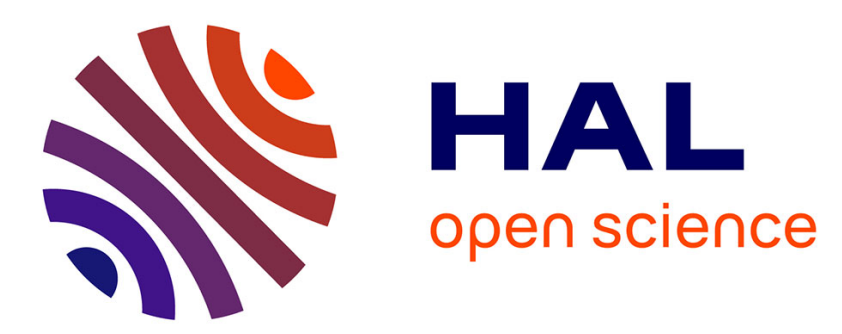

\title{
A multivariate methodology to distinguish among wine Appellations of Origin
}

\author{
María Reyes González-Centeno, Simón Adrover-Obrador, Susana Simal, \\ Miquel Angel Frau, Antoni Femenia, Carmen Rosselló
}

\section{- To cite this version:}

María Reyes González-Centeno, Simón Adrover-Obrador, Susana Simal, Miquel Angel Frau, Antoni Femenia, et al.. A multivariate methodology to distinguish among wine Appellations of Origin. Agronomy for Sustainable Development, 2015, 35 (1), pp.295-304. 10.1007/s13593-014-0242-5 . hal-01284263

\section{HAL Id: hal-01284263 \\ https://hal.science/hal-01284263}

Submitted on 7 Mar 2016

HAL is a multi-disciplinary open access archive for the deposit and dissemination of scientific research documents, whether they are published or not. The documents may come from teaching and research institutions in France or abroad, or from public or private research centers.
L'archive ouverte pluridisciplinaire HAL, est destinée au dépôt et à la diffusion de documents scientifiques de niveau recherche, publiés ou non, émanant des établissements d'enseignement et de recherche français ou étrangers, des laboratoires publics ou privés. 


\title{
A multivariate methodology to distinguish among wine Appellations of Origin
}

\author{
María Reyes González-Centeno • \\ Simón Adrover-Obrador • Susana Simal • \\ Miquel Angel Frau • Antoni Femenia • Carmen Rosselló
}

Accepted: 11 July 2014 /Published online: 12 August 2014

(C) INRA and Springer-Verlag France 2014

\begin{abstract}
The legal recognition of the geographical origin of wines, named Appellation of Origin, is of great interest for both consumers and producers, since it provides decisive criteria of acceptability in terms of guaranteed quality. However, when wines are considered to differ among the viticultural regions where they are produced, it is difficult to verify if the distinction is actually linked to their provenance, or, conversely if it is merely due to the work of the winemaker. Therefore, there is a need for methods that separate the effect of the geographical location from that of the human factor. Thirteen Merlot and 14 Cabernet Sauvignon vineyards were selected from two Appellations of Origin, named Binissalem and Pla $i$ Llevant, located in the Balearic Islands (Spain). Grapes and soils were sampled evenly over the whole surface of each vineyard. Climatic and landscape conditions were also registered at each site. Univariable analysis was performed to evaluate the effect of the Appellation of Origin on the color intensity, the color tonality and the phenolic content of grapes, the silts, sands, clays and carbonate content of soils, the rainfall, the maximum and minimum temperature, and the elevation of the vineyards in 2009 and 2010. Based on the soil, climate, and landscape characteristics, a Partial Least Square Discriminant Analysis was used to discriminate
\end{abstract}

\footnotetext{
M. R. González-Centeno $(\bowtie) \cdot S$. Simal · A. Femenia $\cdot$ C. Rosselló Department of Chemistry, Universitat de les Illes Balears, Ctra. Valldemossa, Km 7.5, 07122 Palma de Mallorca, Spain

e-mail: reyes.gonzalez.centeno@gmail.com

S. Adrover-Obrador

Institute of Agricultural and Fishing Research and Training (IRFAP), Government of the Balearic Islands, c/d'Eusebi Estada, 145, 07009 Palma de Mallorca, Spain

\section{A. Frau}

Institut de Qualitat Agroalimentària (IQUA). Conselleria d'Agricultura, Medi Ambient i Territori, Government of the Balearic Islands, c/Foners, 10, 07006 Palma de Mallorca, Spain
}

between both Appellations of Origin. Results showed that a particular agroclimatic terroir may be defined for each Appellation of Origin. Indeed, this multivariate analysis led to a correct classification rate of $95 \%$ for both 2009 and 2010 models and a prediction accuracy higher than $85.7 \%$. The research here proposed a methodology suitable for evaluating the appropriateness of contiguous viticultural Appellations of Origin in terms of a whole terroir concept, without considering the human factor.

Keywords Terroir · Appellation of Origin - Geographical indication · Grapes $\cdot$ Merlot $\cdot$ Cabernet Sauvignon $\cdot$ Partial least squares discriminant analysis

\section{Introduction}

Wine is a complex matrix whose composition is dependent on grape variety, climate, and soil conditions of the production area, as well as on the viticultural and winemaking techniques used (Pérez-Magariño and González-San José 2001). Most wine components, or at least its precursors, come directly from the vineyard and define a representative fingerprint in the grapes which enhances a personalized and particular character in wines.

The legal recognition of the geographical origin of wines, by certifications such as the Appellations of Origin or the Protected Geographical Indications, is of great interest to both consumers and producers, since it ensures a certain quality level and helps to maintain a certain individuality within a global market (Fabani et al. 2010). To achieve these certifications, particular grape varieties must be cultivated in a well-defined geographical area and the wines subjected to regulations and controls carried out by a regulatory council (Pérez-Magariño et al. 2001). According to the European legislation (Council Regulation no. 479/2008), this recognition of authenticity is based on the essential attribution of their 
quality and particular characteristics to the geoclimatic environment involved in vineyard development and wine production.

According to the literature, geographical origin plays an important role in distinction of wines, since it may explain the similarities between wines from the same vine-growing region and the main differences between those from different ones. To establish wine differentiation, multivariate statistical techniques such as discriminant analysis, partial least squares discriminant analysis, and/or clustering analysis are usually applied. In the last decade, several reports have attempted to identify and differentiate among musts and/or wines according to their geographical origin, grape variety, and/or vintage year, among other discrimination criteria. For this purpose, the abovementioned multivariate techniques have been recently applied on the physicochemical, mineral, and/or sensory characteristics of wines (Cynkar et al. 2010; Fabani et al. 2010; Jaitz et al. 2010; Sáenz et al. 2010; Martin et al. 2012; Azcarate et al. 2013; Roullier-Gall et al. 2014). Nevertheless, none of these studies explains their geographical differentiation on the basis of a whole terroir concept defined by the agroclimatic attributes of the viticultural region to which wines belong. Only González-Centeno et al. (2013) proposed the application of principal component analysis to the grape, soil, climate, and landscape attributes of the vine ecosystem as a multivariate methodology to evaluate the appropriateness of the Protected Geographical Indications recognition in a specific wine region. These authors achieved the differentiation among Protected Geographical Indications from the viticultural area of the Balearic Islands (Spain), demonstrating their historical existence and explaining it, in a first approach, on a more geographical basis without considering the human factor. The question is if such methodology, based on a whole terroir concept (soil, climate, and landscape), is still applicable when the studied wine certification areas border each other rather than being located on discrete islands, in different countries, and/or at a different latitude within the same country. When adjacent vine-growing regions are considered, the nuances of both climate and landscape, as well as soil composition, may not be accentuated enough. Thus, geographical differentiation of their wine certifications may be not so clear.

To address this issue, the present research is aimed at evaluating the potential use of a multivariate approach, based on the soil, climate, and landscape conditions involved in vineyard development, to differentiate between adjacent Appellations of Origin. For this purpose, two close vinegrowing areas of Mallorca (Balearic Islands, Spain), legally recognized as Appellations of Origin, were chosen (Fig. 1). Both, Appellation of Origin Binissalem and Appellation of Origin Pla i Llevant, have well-defined geographical limits and their differentiation has been traditionally accepted. Nevertheless, their differences have only recently been validated according to their geographical origin as required by the Council Regulation no. 479/2008 (European Commission 2008). The present study has contributed to this validation.

\section{Materials and methods}

A representative number of both Merlot and Cabernet Sauvignon vineyards was selected from each of the two viticultural Appellations of Origin located on Mallorca (Balearic Islands, Spain) (55\% of participation for Appellation of Origin Binissalem, and $70 \%$ for Appellation of Origin Pla i Llevant). Altogether, 13 Merlot and 14 Cabernet Sauvignon vineyards participated in this study during two consecutive vintages, 2009 and 2010. For Merlot, five were from Appellation of Origin Binissalem and eight from Appellation of Origin Pla i Llevant; whereas for Cabernet Sauvignon, six and eight vineyards were considered, respectively, for Appellation of Origin Binissalem and Appellation of Origin Pla i Llevant. Grapes and soils were sampled evenly over the whole surface of all these vineyards. Climatic and landscape conditions were also recorded at each site.

In general, all the vineyards selected have been traditionally managed according to the same training system, rootstock, grapevine spacing, and irrigation conditions. All the vines presented an average age of 15 years.

\subsection{Grapes}

A representative grape sample was collected from each vineyard aforementioned, according to the guidelines previously reported by González-Centeno et al. (2013). Briefly, facing rows were sampled in zigzag at the same time (in total, from five to ten depending on the vineyard surface), by collecting grape berries every three vines. At these positions, clusters located at different heights of the vine and under different sunshine conditions were considered. To avoid the heterogeneity within the cluster, grape berries were randomly collected at the upper, middle, and lower positions and both the external and internal faces of the cluster. Grape berries of different size and ripening degree were considered, by harvesting a minimum of $3 \mathrm{~kg}$ of grape sample per vineyard.

Once in the laboratory, all grape samples were subjected to a maceration process consisting of an incubation of grapes mashed with ethanol $57 \%$ during $24 \mathrm{~h}$ at $24{ }^{\circ} \mathrm{C}$ in the dark. Chromatic characteristics of the fresh macerated grape juice were estimated by assessing both color intensity and tonality parameters (Council Regulation no. 2676/90) with a MultiSkan Spectrum spectrophotometer (Thermo Fisher Scientific, Vanda, Finland). Color intensity was calculated as 

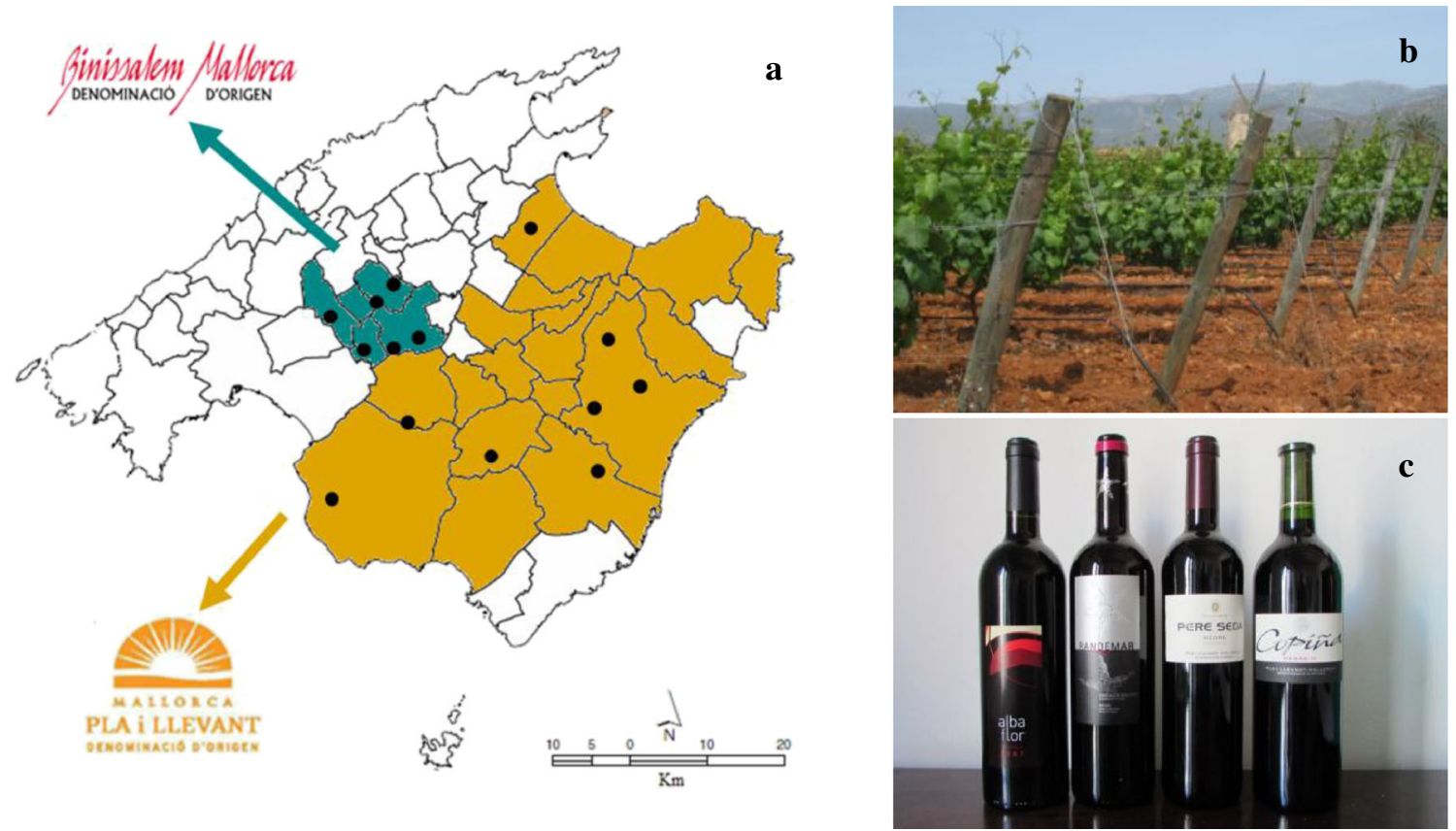

Fig. 1 Winemaking with Appellation of Origin in Mallorca (Balearic Islands, Spain). The photo on the left (a) displays the geographical area covered by Appellation of Origin Binissalem and Appellation of Origin $\mathrm{Pla}$ i Llevant, as well as their official labeling and the geolocation of vineyards considered in the present study. Each point on the map

the sum of absorbances at 420, 520, and $620 \mathrm{~nm}$, whereas tonality was determined as the ratio between absorbance at 420 and $520 \mathrm{~nm}$. Total phenolic content of the macerated grape juice was also spectrophotometrically evaluated in accordance with the Folin Ciocalteu assay described by González-Centeno et al. (2012). Diluted solutions of the macerated grape juice $(1: 20, v / v)$ were prepared in EtOH $57 \%$ for this measurement. Absorbance was recorded at a wavelength of $765 \mathrm{~nm}$ and a gallic acid calibration curve was used for calculation of total phenolic results.

\subsection{Soil}

All soil samples were collected within a maximum of 2 weeks during vine dormancy, at the end of March - beginning of April, either in 2009 or 2010 vintage. According to the procedure reported by González-Centeno et al. (2013), a systematic sampling was carried out in each vineyard. Specifically, 20 to 30 sampling points evenly distributed over the whole surface of each single vineyard were considered, in order to get a whole representative soil sample per vineyard (from 10 to $15 \mathrm{~kg}$ ). Individual samples at these points were taken from a depth of $0-20 \mathrm{~cm}$. From the representative soil samples collected, texture (percentage of silts, sands, and clays) and carbonate content were measured in triplicate, by using USDA classification and the Bernard calcimeter (Pobel, Madrid, Spain), respectively. represents both the corresponding Merlot and Cabernet Sauvignon vineyards per wine cellar participating. The upper photo (b) shows a Merlot vineyard belonging to Appellation of Origin Binissalem. And the lower photo (c) depicts some wine bottles of both Appellations of Origin

\subsection{Climatic and landscape data}

Rainfall, maximum and minimum temperature, and elevation descriptors were considered. Specifically, the climatic data was provided by the National Institute of MeteorologyMeteorological Centre of the Balearic Islands; and elevation data, by the Service of Geographic Information Systems and Remote Sensing (SSIGT) of the University of the Balearic Islands.

ArcGis 9.3.1 software (ESRI-Environmental Systems Research Institute Inc., Redlands, CA, USA) was used to obtain the geolocated climatic and landscape data for each vineyard considered in the study.

Climatic data initially consisted of monthly information of the 2009 and 2010 vintages, but only the mean values for May conditions were used to characterize vineyards from both Appellations of Origin, since the flowering period of the vines, especially influenced by climatic conditions, mainly takes place during this month (Hidalgo 2002).

\subsection{Statistical analysis}

The effect of the Appellation of Origin on the color intensity, the color tonality, and the phenolic content of Merlot and Cabernet Sauvignon grapes; the silts, sands, clays, and carbonate content in soils; the rainfall; the maximum and minimum temperature; and the elevation of the vineyards were assessed for two consecutive vintages by using a Student's $t$ 
test. Normality and homoscedasticity of residuals were evaluated for all tests, by using the Shapiro-Wilk test and Levene's test, respectively. The $t$ test was substituted by the nonparametric Wilcox test when normality and/or homoscedasticity of residuals were not met. Differences at $p<0.05$ were considered to be statistically significant. All these statistical analyses were carried out using $\mathrm{R}$ software (version 3.0.2, R Foundation for Statistical Computing, Vienna, Austria).

For further chemometrical processing, samples belonging to the same Appellation of Origin and vintage year were assigned by the same category, regardless of the grape variety. Based on the soil, climate, and landscape characteristics, a Partial Least Square Discriminant Analysis (PLS-DA) was used as multivariate tool to discriminate between both Appellations of Origin, separately for each vintage year. This supervised pattern recognition method was performed by using the XLSTAT software (version 2014.2.07, Copyright Addinsoft 1995-2014). All data were autoscaled for each variable. A cross-validation procedure was coupled to the PLS-DA method to assess the accuracy of classification and the prediction capacity of the discriminant model. Therefore, two sample sets were considered at the multivariate treatment of the data from each vintage year: (i) the training set (20 samples, $75 \%$ of the dataset) was used for developing the classification model; and (ii) the prediction set (7 samples randomly selected, $25 \%$ of the dataset), for validating the model performance.

\section{Results and discussion}

Grape (phenolic content, color intensity, and tonality), soil (silts, sands, clays, and carbonate content), climate (rainfall, minimum and maximum temperature), and landscape (elevation) mean characteristics of the vineyards from Appellation of Origin Binissalem and Appellation of Origin Pla i Llevant are depicted in Figs. 2 and 3. The variables analyzed corresponded to those previously described by González-Centeno et al. (2013) as the more discriminant ones to differentiate among the four Protected Geographical Indications located at the same vine-growing area (Balearic Islands, Spain).

With regard to grape features, significant differences $(p<0.05)$ were observed between Appellation of Origin Binissalem and Appellation of Origin Pla i Llevant for the phenolic content, the color intensity, and tonality — within all categories considered, except for Cabernet Sauvignon cultivar in 2009- (Fig. 2). In general terms, regardless of the cultivar and the vintage year, grapes from Appellation of Origin Pla i Llevant denoted a higher color intensity, a lower color tonality, and a greater phenolic content than grapes from Appellation of Origin Binissalem $(p<0.05)$.

For both vintage years considered, the vineyard soils from Appellation of Origin Pla i Llevant tended to be slightly richer in silts and sands, but poorer in clays and carbonates, than soils from Appellation of Origin Binissalem. However, differences were not significant, for none of the four parameters $(p>0.05)$ (Fig. 3a-d). Such results may be related to Majorcan geology, since soils from Appellation of Origin Binissalem are mainly constituted by quaternary calcareous red clays, while Appellation of Origin Pla i Llevant is set on several and different geological formations (geological cartography from Instituto Geológico y Minero de España). The spatial variability observed within and between vineyards from the same Appellation of Origin, and the contiguous location of both Appellation of Origin Binissalem and Appellation of Origin Pla i Llevant, since they border each other on a discrete Mediterranean island, may have resulted in the absence of significant differences for the four parameters considered.

Regarding the climatic variables, it will be noticed that the rainfall regimen was more important in $2010(99.9 \pm 7.8 \mathrm{~mm}$ for Appellation of Origin Binissalem and $70.5 \pm 45.2 \mathrm{~mm}$ for Appellation of Origin Pla i Llevant) than in 2009 (10.2 \pm $1.8 \mathrm{~mm}$ for Appellation of Origin Binissalem and 19.8土 $6.9 \mathrm{~mm}$ for Appellation of Origin Pla i Llevant) (Fig. 3e). Furthermore, in both 2009 and 2010, significant differences $(p<0.05)$ were found between Appellation of Origin Binissalem and Appellation of Origin Pla i Llevant. In particular, the lowest mean rainfall values in 2009 and the greatest

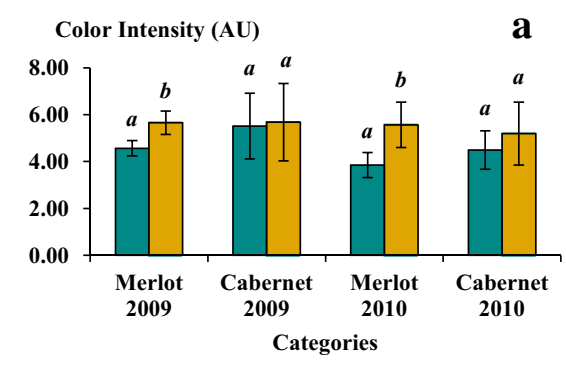

Fig. 2 Analysis of variance performed to evaluate the existence of significant differences between grapes from the Appellation of Origin Binissalem (first column within each category, yellow column) and the Appellation of Origin Pla i Llevant (second column within each category,
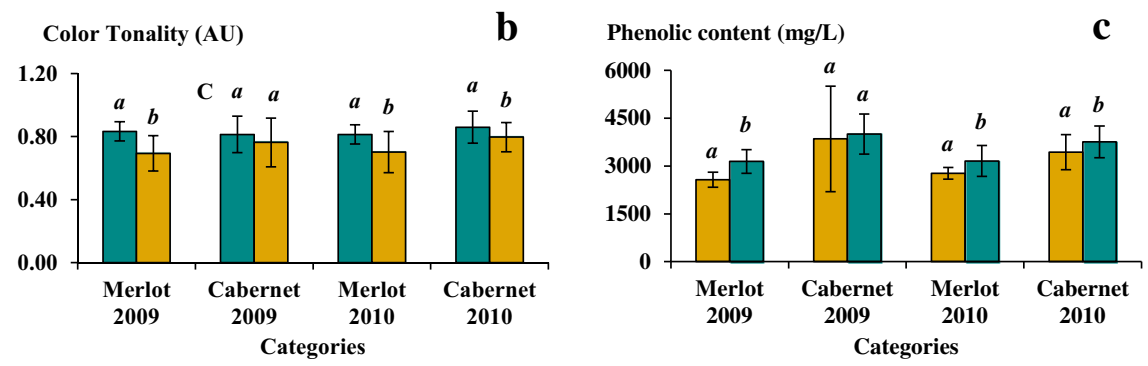

turquoise column) for the categories considered (Merlot 2009, Cabernet Sauvignon 2009, Merlot 2010, and Cabernet Sauvignon 2010), with regard to the color intensity (a), color tonality (b), and total phenolic content (c). $A U$ absorbance units 

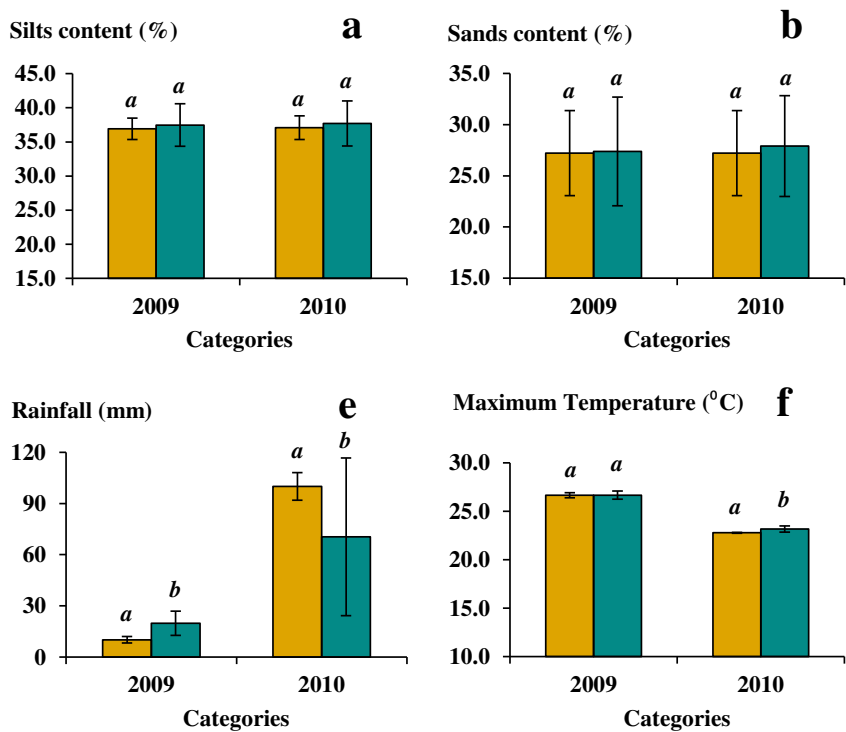

Fig. 3 Analysis of variance performed to evaluate the existence of significant differences between the Appellation of Origin Binissalem (first column within each category, yellow column) and the Appellation of Origin Pla i Llevant (second column within each category, turquoise column), with regard to the soil (a silts content, b sands content, $\mathbf{c}$ clays

ones in 2010 were registered in vineyards from Appellation of Origin Binissalem. The fact that both Appellations of Origin differed significantly with regard to their rainfall regime is mainly supported by the geographical features of Mallorca Island. Specifically, vineyards from Appellation of Origin Binissalem are located in the heart of the island at a mean elevation of $119 \pm 7 \mathrm{~m}$ above sea level, and protected from cold north winds by the Tramuntana Mountains (west coast of the island). Meanwhile, vineyards from Appellation of Origin Pla i Llevant are situated in the southeastern part of the island, at a lower altitude than those of Appellation of Origin Binissalem $(p<0.05)$ (Fig. 3h), and highly influenced by proximity to the sea (Rosselló et al. 2003).

Generally, maximum and minimum mean temperatures of May were higher in 2009 than in 2010 in Mallorca Island (Fig. 3f, g). No significant differences $(p>0.05)$ were detected between both Appellations of Origin with regard to the temperature in 2009. In contrast, slightly higher minimum and maximum temperatures were recorded in vineyards from Appellation of Origin Pla i Llevant in $2010(p<0.05)$. It is important to point out that despite being statistically significant, temperature nuances between both Appellations of Origin in 2010 were not very accentuated, once again due to their bordering location.

From the eleven initial variables investigated, only those referring to soil, climate, and landscape characteristics were considered in carrying out the Partial Least Squares Discriminant Analysis on the experimental database of each vintage year, in order to (i) characterize terroir differences between Appellation of Origin Binissalem and Appellation
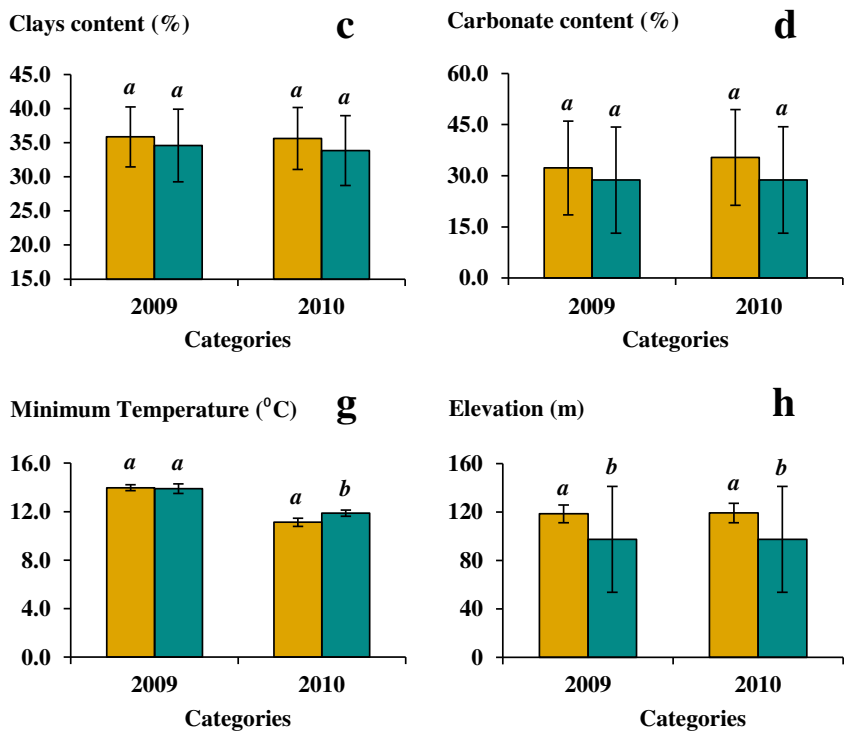

content, $\mathbf{d}$ carbonate content), climate (e rainfall, $\mathbf{f}$ maximum temperature, g minimum temperature) and landscape (h elevation) characteristics of their vineyards for vintages 2009 and 2010. Letters within the same category show the significant differences between Appellation of Origin Binissalem and Appellation of Origin Pla i Llevant $(\mathrm{p}<0.05)$

of Origin Pla i Llevant and (ii) to relate them to the differences observed in grape characteristics of Merlot and Cabernet Sauvignon cultivars.

The Partial Least Squares Discriminant Analysis models for 2009 and 2010 vintages were both obtained using two principal components, which jointly explained 53 and $78 \%$ of the total variance in the original datasets, respectively. The corresponding correlation maps of the explanatory variables (silts, sands, clays, and carbonate content in soils, rainfall, minimum and maximum temperature, elevation) and the studied categories (Appellation of Origin Binissalem and Appellation of Origin Pla i Llevant) are depicted in Fig. 4.

For both vintage years, the categories Appellation of Origin Binissalem and Appellation of Origin Pla i Llevant were clearly separated one from another. Since only the soil, climate, and landscape characteristics of their vineyards were considered for the multivariate treatment of the data, a different agroclimatic terroir may be defined for each of the Appellations of Origin. It is important to point out that this differentiation is closely linked to the vintage effect, since the particular terroirs observed in 2009 slightly changed in 2010 due to the climatic differences at each vine-growing region from one year to the other.

Regardless of the vintage year, the terroir of the Appellation of Origin Binissalem was mainly characterized by the elevation of their vineyards and the higher clays and/or carbonate content of their soils. Meanwhile, the terroir of the Appellation of Origin Pla i Llevant was specially defined by the greater sands and/or silts content of their vineyard soils. In vintage 2009, the terroir of the Appellation of Origin Pla i 
Fig. 4 Correlation map of the explanatory variables (soil content of silts, sands, clays and carbonate, rainfall, minimum and maximum temperature, elevation) and the studied categories (Appellation of Origin Binissalem and Appellation of Origin Pla i Llevant) on the first two components of the Partial Least Squares Discriminant Analysis model for the 2009 (a) and 2010

(b) vintages. Explanatory variables are represented by continuous red lines ending in red points, whereas categories are represented by discontinuous blue lines ending in blue squares. $A O$ Appellation of Origin
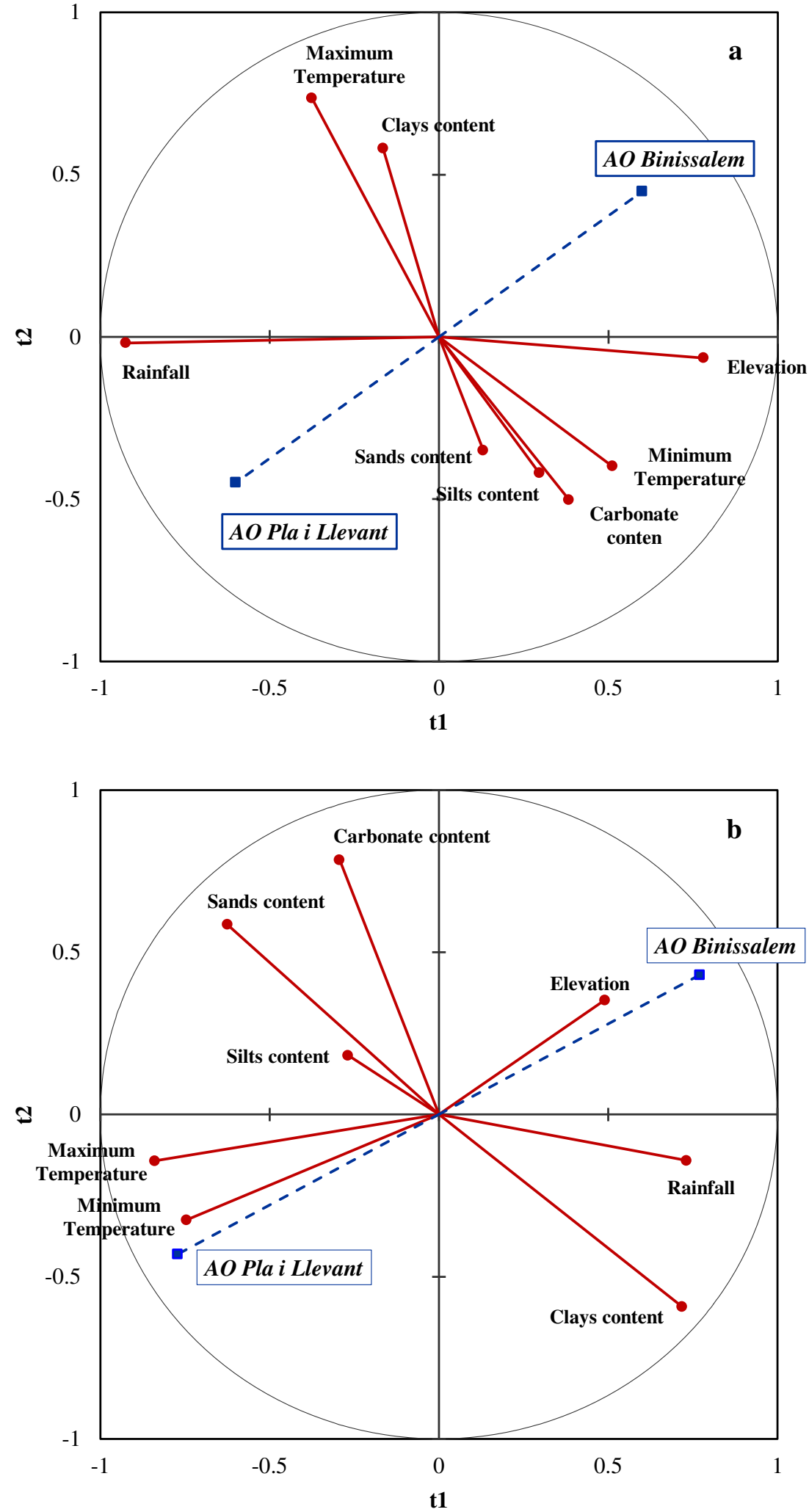

Llevant was additionally differentiated from the terroir of the Appellation of Origin Binissalem because of the greater rainfall regime registered at that vine-growing region, and vice versa for the vintage 2010 (Fig. 4). As observed, minimum and maximum temperatures did not participate in the discrimination between both Appellations of Origin in 2009. Nevertheless, these two variables played a specific role in terroir differentiation in vintage 2010, since higher 
temperature values were registered at the vineyards from Appellation of Origin Pla i Llevant.

According to the variable importance in the projection model (variables with VIP values close to or greater than 1 are considered important in the given model), rainfall and elevation were those with the major impact on the 2009 model response (VIP values $\geq 1.2$ at $p<0.05$ ). Meanwhile, variables with the major influence on the terroir differentiation for the 2010 model were both temperature parameters; rainfall; and carbonate, clays, and sands content in soil (VIP values $\geq 0.8$ at $p<0.05$ ), in this decreasing order of impact.

It is important to point out that the different terroirs described evidence the geographical entail of both Appellations of Origin to their winemaking area, as required by the European Council Regulation no. 479/2008. Furthermore, they may justify the phenolic and color differences previously observed between grapes from Appellation of Origin Binissalem and Appellation of Origin Pla i Llevant, for both Merlot and Cabernet Sauvignon cultivars (Fig. 2).

Several studies have previously reported the individual impact of soil (Van Leeuwen et al. 2004; Andrés de Prado et al. 2007; Gómez-Míguez et al., 2007), climate (Van Leeuwen et al. 2004; Sadras and Soar 2009), or landscape (Mateus et al. 2001; Mateus et al. 2002) on the grape yield and/or composition. Nevertheless, research is rather scarce in explaining differences between grape characteristics with regard to a whole terroir concept - based on the combined effect of the soil, climate and landscape of the vineyard - and even more scarce when it is used to delineate vine-growing regions and/or to validate the appropriateness of their corresponding wine certifications of quality. For these purposes, wine composition and/or flavor is usually considered. Nonetheless, in line with the present study, Priori et al. (2014) conducted a multivariate approach to investigate relationships between soil, climate, and morphology of the vineyard with viticultural features of grapes (such as yield or sugar accumulation, among others), and to develop a terroir mapping model in the province of Siena (Italy). These authors discriminated nine different terroirs on the basis of elevation; mean annual temperature; annual precipitation; and clay, sand, and gravels content of soil, among other variables, and characterized the historical Appellations of Origin of the Siena region by one or more of those terroirs. Yau et al. (2013) also focused on environmental factors (elevation, rainfall, soil parameters, among others) that impact grape production to accurately characterize and delineate 13 recognized viticultural areas of the inland Pacific Northwest of America.

Tables 1 and 2 summarize the PLS-DA classification and prediction results of samples from 2009 and 2010, respectively, according to their geographical origin or vine-growing region. Regardless of the vintage considered, a correct global classification of $95 \%$ of samples was noticed according to the Appellation of Origin they belong to. For the vintage 2009,
Table 1 Results of the classification of the PLS-DA model according to the Appellation of Origin for the vintage 2009

\begin{tabular}{lllll}
\hline & $\begin{array}{l}\text { AO } \\
\text { Binissalem }\end{array}$ & $\begin{array}{l}\text { AO Pla i } \\
\text { Llevant }\end{array}$ & Total & $\begin{array}{l}\text { Percent correct } \\
\text { classification }\end{array}$ \\
\hline $\begin{array}{l}\text { Training set } \\
\text { AO Binissalem }\end{array}$ & 10 & 0 & 10 & 100.0 \\
AO Pla i Llevant & 1 & 9 & 10 & 90.0 \\
Total & 11 & 9 & 20 & 95.0 \\
Prediction set & & & & \\
AO Binissalem & 3 & 0 & 3 & 100.0 \\
AO Pla i Llevant & 1 & 3 & 4 & 75.0 \\
Total & 4 & 3 & 7 & 85.7 \\
\hline
\end{tabular}

$A O$ Appellation of Origin

the greatest percentage of correctly classified cases (100\% of correct classification) corresponded to the samples from Appellation of Origin Binissalem. Meanwhile, for samples from Appellation of Origin Pla i Llevant, the proper prediction of the category was slightly reduced to $90 \%$ (Table 1). In contrast, for the vintage 2010, the category Appellation of Origin Pla i Llevant achieved $100 \%$ of global assignment of their corresponding samples, and in the category Appellation of Origin Binissalem, $87.5 \%$ of samples were correctly classified (Table 2). In spite of the contiguity of the studied Appellations of Origin, in both classification models, only one sample was mistakenly assigned to its original category. Thus, an appropriate classification according to the geographical origin is shown by the application of Partial Least Squares Discriminant Analysis to the experimental dataset. This might be explained by the fact that the PLS-DA algorithm maximizes the variance between categories rather than within the category (Azcarate et al. 2013).

With regard to the model prediction, correct global classification rates of 87.5 and $100 \%$ were achieved for the prediction sample sets of vintage 2009 and 2010, respectively.

Table 2 Results of the classification of the PLS-DA model according to the Appellation of Origin for the vintage 2010

\begin{tabular}{lllll}
\hline & $\begin{array}{l}\text { AO } \\
\text { Binissalem }\end{array}$ & $\begin{array}{l}\text { AO Pla i } \\
\text { Llevant }\end{array}$ & Total & $\begin{array}{l}\text { Percent correct } \\
\text { classification }\end{array}$ \\
\hline Training set & & & & \\
$\quad$ AO Binissalem & 7 & 1 & 8 & 87.5 \\
AO Pla i Llevant & 0 & 12 & 12 & 100.0 \\
Total & 7 & 13 & 20 & 95.0 \\
Prediction set & & & & \\
AO Binissalem & 3 & 0 & 3 & 100.0 \\
AO Pla i Llevant & 0 & 4 & 4 & 100.0 \\
Total & 3 & 4 & 7 & 100.0 \\
\hline
\end{tabular}

$A O$ Appellation of Origin 
For the vintage 2009, only one sample from Appellation of Origin Pla i Llevant was misclassified in the prediction, which resulted in a correctly classified rate of $75 \%$ for this category (Table 1). In the case of vintage 2010, the prediction accuracy for both categories was up to $100 \%$, since every sample from both Appellations of Origin was successfully predicted (Table 2).

The goodness of the PLS-DA models was evaluated by the coefficient of determination $\left(\mathrm{R}^{2}\right)$ and the prediction ability measured as the area under the curve at the sensitivity vs. (1-specificity) plot. The coefficient of determination is a measure of how well the model fits the experimental data. In the present research, $\mathrm{R}^{2}$ values were 0.53 and 0.78 for the models of 2009 and 2010, respectively. According to the literature, a large $\mathrm{R}^{2}$ (closer to 1 ) is a necessary condition for a good model, but it is not sufficient, since a good prediction ability should be given (Cheng et al. 2014). The area under the curve at the sensitivity vs. (1-specificity) plot ought to be as close to 1 as possible, since that means $100 \%$ sensitivity (no false negatives) and $100 \%$ specificity (no false positives). In the present research, values of 0.95 and 1.00 were calculated for the 2009 and 2010 PLS-DA models, respectively. These results ensured the accuracy of the predictions given and showed the good capacity of both PLS-DA models to predict new data.

According to the obtained results, differentiation between the two viticultural Appellations of Origin considered in the present research was demonstrated, based on the soil, climate, and landscape attributes of their vineyards, without considering the human factor. Each terroir defined both the vine growth as the grape properties at the corresponding Appellation of Origin, revealing some differences which in turn will be reflected, or even amplified, in wine flavor and aroma.

Mulet et al. (1992) and Forcén et al. (1993) considered the same viticultural regions as the present research, previous to their legal recognition as Appellations of Origin. Both authors investigated the effect of the geographical origin on the differentiation of musts and/or wines from both regions, based on oenological parameters and volatile aroma composition, respectively. In comparison with the present investigation, lower percentages of correct classification were obtained with regard to the geographical origin (62-90\%).

The degree of correct classification achieved in the present research is comparable to the results previously reported in the literature for the geographical differentiation of wines according to their physicochemical, mineral, and/or sensory characteristics. For example, Jaitz et al. (2010) evaluated the effect of geographical origin on the differentiation of red wines from 11 viticultural Austrian regions, by applying discriminant analysis on their phenolic composition. These authors reported 84 $100 \%$ of correct classification. Similar results were described by Martin et al. (2012) for the discrimination of white and red wines from different regions of Australia, based on their elemental composition (83-100\% of correct classification).
Cynkar et al. (2010) analysed Tempranillo wines produced in Australia and Spain by a mass spectrometry-based electronic nose instrument. A partial least squares discriminant analysis of the data led to a correct classification of $85 \%$ of wines according to their geographical origin.

Other authors have recently reported similar percentages of correct classification by analyzing discrimination of musts and/or wines according to their geographical origin or viticultural region, on the basis of their phenolic composition (Franquet-Griell et al. 2012; Roullier-Gall et al. 2014), chemical attributes (Rezaei and Reynolds 2010; Serrano-Lourido et al. 2012; Azcarate et al. 2013), aroma profile (Sáenz et al. 2010), or elemental composition (Gonzálvez et al. 2009; Paneque et al. 2009; Fabani et al. 2010; Paneque et al. 2010; Razic and Onjia 2010; Bentlin et al. 2011).

Meanwhile, Soufleros et al. (2003) failed to discriminate adequately among white wines from six Greek viticultural regions based on their amino acid content. And Kontkanen et al. (2005) reported an incomplete differentiation among red wines from three Canadian regions on the basis of their sensory characterization.

In contrast with the present research, most of these studies include: (i) the human factor; and (ii) discriminant variables used to differentiate among wines from different Appellations of Origin, viticultural regions, or countries, which consist of physicochemical characteristics of the wines and not of the geographical environment in which they originated.

Each viticultural region has its own oenological tradition, heritage culture, and history, all of them highly conditioned by the human factor in winemaking. Thus, when wines are considered to differentiate among their regions of origin, and only composition parameters are examined as discriminant variables, it is difficult to verify if the distinction is actually linked to the geographical origin and agroclimatic environment involved in vineyard development, or, conversely it is simply the result of the winemakers' work.

For this reason, the research here analyzes a combination of the soil, climate, and landscape attributes of the viticultural regions considered, to characterize the terroirs which define them and justify the differences between their grape properties. Without considering the human impact, the multivariate approach carried out results in a significant differentiation among samples from Appellation of Origin Binissalem and Appellation of Origin Pla i Llevant. In this context, the appropriateness of their historical existence in the Balearic Islands (Mallorca, Spain) has been corroborated and explained on a more geographical basis.

\section{Conclusions}

The present research proposes the application of Partial Least Squares Discriminant Analysis to the soil, climate, and 
landscape characteristics of the vineyards as a multivariate approach to evaluate and assess the effect that the agroclimatic fingerprint exerts on the vineyards differentiation according to the Appellation of Origin they belong to.

Despite the contiguity of Appellation of Origin Binissalem and Appellation of Origin Pla i Llevant, a particular agroclimatic terroir was observed for each wine certification. Phenolic and color differences observed in their corresponding grapes, which in turn will be reflected or even amplified in wine flavor and aroma, may be justified by these different terroirs. The application of Partial least Squares Discriminant Analysis allowed an appropriate classification of vineyards according to their Appellation of Origin over two consecutive years ( $95 \%$ of correct classification in all cases), the prediction accuracy of the models being $\geq 85.7 \%$.

Furthermore, this study has provided the regulatory boards with the scientific evidence required in order to demonstrate the geographical entail of both Balearic Appellations of Origin to their winemaking area as specified by the Council Regulation no. 479/2008. In this context, the present research provides a valid methodology to evaluate and explain the historical existence and appropriateness of other viticultural appellations on a more geographical basis, in terms of a whole terroir concept without considering the human factor.

Acknowledgements The authors acknowledge the financial support of the Balearic Islands Government (Research Fellowship BII10/08), the European Regional Development Fund (FEDER, 57/2011), and the Spanish Government (AGL2012-34627). The authors thank the wine cellars from both Appellation of Origin Binissalem and Appellation of Origin Pla i Llevant that participated in the study. They would also like to thank the Service of Geographic Information Systems and Remote Sensing (SSIGT) of the University of the Balearic Islands for their technical support, and Dr. L. Marchand and Dr. J.P. Maalouf for their advice in statistics.

\section{References}

Andrés de Prado R, Yuste-Rojas M, Sort X, Andrés-Lacueva C, Torres M, Lamuela-Raventós RM (2007) Effect of soil type on wines produced from Vitis vinifera L. Cv. Grenache in commercial vineyards. J Agric Food Chem 55:779-786. doi:10.1021/jf062446q

Azcarate SM, Cantarelli MA, Pellerano RG, Marchevsky EJ, Camina JM (2013) Classification of Argentinean Sauvignon Blanc wines by UV spectroscopy and chemometric methods. J Food Sci 78:C432C436. doi:10.1111/1750-3841.12060

Bentlin FRS, Pulgati FH, Dressler VL, Pozebon D (2011) Elemental analysis of wines from South America and their classification according to country. J Braz Chem Soc 22:327-336. doi:10.1590/ S0103-50532011000200019

Cheng P, Fan W, Xu Y (2014) Determination of Chinese liquors from different geographic origins by combination of mass spectrometry and chemometric technique. Food Control 35:153-158. doi:10. 1016/j.foodcont.2013.07.003

Cynkar W, Dambergs R, Smith P, Cozzolino D (2010) Classification of Tempranillo wines according to geographic origin: combination of mass spectrometry based electronic nose and chemometrics. Anal Chim Acta 660:227-231. doi:10.1016/j.aca.2009.09.030

Fabani MP, Arrúa RC, Vázquez F, Dáaz MP, Baroni MV, Wunderlin DA (2010) Evaluation of elemental profile coupled to chemometrics to assess the geographical origin of Argentinean wines. Food Chem 119:372-379. doi:10.1016/j.foodchem.2009. 05.085

Forcén M, Berna A, Mulet A (1993) Using aroma components to characterize Majorcan varietal red wines and musts. Food Sci TechnolLeb 26:54-58. doi:10.1006/fstl.1993.1010

Franquet-Griell H, Checa A, Núñez O, Saurina J, Hernández-Cassou S, Puignou L (2012) Determination of polyphenols in Spanish wines by capillary zone electrophoresis. Application to wine characterization by using chemometrics. J Agric Food Chem 60:8340-8349. doi: $10.1021 / \mathrm{jf3} 32078 \mathrm{j}$

González-Centeno MR, Jourdes M, Femenia A, Simal S, Rosselló C, Teissedre P-L (2012) Proanthocyanidin composition and antioxidant potential of the stem winemaking byproducts from 10 different grape varieties (Vitis vinifera L.). J Agric Food Chem 60:1185011858. doi:10.1021/jf303047k

González-Centeno MR, Simal S, Femenia A, Frau M, Rosselló C (2013) Identification of behaviour patterns of viticultural regions according to their agroclimatic fingerprint and grape characteristics. Aust J Grape Wine R 19:53-61. doi:10.1111/j.1755-0238.2012.00207.x

Gonzálvez A, Llorens A, Cervera ML, Armenta S, De la Guardia M (2009) Elemental fingerprint of wines from the protected designation of origin Valencia. Food Chem 112:26-34. doi:10.1016/j. foodchem.2008.05.043

Gómez-Míguez MJ, Gómez-Míguez M, Vicario IM, Heredia FJ (2007) Assessment of colour and aroma in white wines vinifications: effects of grape maturity and soil type. J Food Eng 79:758-764. doi:10. 1016/j.jfoodeng.2006.02.038

Hidalgo L (2002) Tratado de viticultura general. Mundi-Prensa, Madrid

Jaitz L, Siegl K, Eder R, Rak G, Abranko L, Koellensperger G, Hann S (2010) LC-MS/MS analysis of phenols for classification of red wine according to geographic origin, grape variety and vintage. Food Chem 122:366-372. doi:10.1016/j. foodchem.2010.02.053

Kontkanen D, Reynolds AG, Cliff MA, King M (2005) Canadian terroir: sensory characterization of Bordeaux-style red wine varieties in the Niagara Peninsula. Food Res Int 38:417-425. doi:10.1016/j. foodres.2004.10.010

Martin AE, Watling RJ, Lee GS (2012) The multi-element determination and regional discrimination of Australian wines. Food Chem 133: 1081-1089. doi:10.1016/j.foodchem.2012.02.013

Mateus N, Machado JM, de Freitas V (2002) Development changes of anthocyanins in Vitis vinifera grapes grown in the Douro Valley and concentration in respective wines. J Sci Food Agric 82:1689-1695. doi:10.1002/jsfa. 1237

Mateus N, Marques S, Gonçalves AC, Machado JM, De Freitas V (2001) Proanthocyanidin composition of red Vitis vinifera varieties from the Douro valley during ripening: influence of cultivation altitude. Am J Enol Viticult 52:115-121

Mulet A, Berna A, Forcén M (1992) Differentiation and grouping characteristics of varietal grape musts and wines from Majorcan origin. Am J Enol Viticult 43:221-226

Paneque P, Álvarez-Sotomayor MT, Clavijo A, Gómez IA (2010) Metal content in southern Spain wines and their classification according to origin and ageing. Microchem J 94:175-179. doi:10.1016/j.microc. 2009.10.017

Paneque P, Álvarez-Sotomayor MT, Gómez IA (2009) Metal contents in "oloroso" sherry wines and their classification according to provenance. Food Chem 117:302-305. doi:10.1016/j.foodchem.2009.04.006

Pérez-Magariño S, González-San José, ML (2001) Differentiation parameters of Ribera del Duero wines from other Spanish denominations of origin. Food Sci Technol Int 7:237-244 
Priori S, Barbetti R, L'Abate G, Bucelli P, Storchi P, Costantini EAC (2014) Natural terroir units, Siena province, Tuscany. J Maps 10: 466-477. doi:10.1080/17445647.2014.885853

Razic S, Onjia A (2010) Trace element analysis and pattern recognition techniques in classification of wine from central Balkan countries. Am J Enol Viticult 61:506-511. doi:10.5344/ajev. 2010.10002

Rezaei JH, Reynolds AG (2010) Characterization of Niagara Peninsula Cabernet Franc wines by sensory analysis. Am J Enol Viticult 61: 1-14. doi:10.1016/j.foodres.2004.10.010

Rosselló C, Bestard I, Cañellas J, Femenia A, Simal S (2003) Conèixer i gaudir els aliments de les Illes Balears. University of the Balearic Islands. Servei de Publicacions i Intercanvi Científic, Palma de Mallorca (Spain)

Roullier-Gall C, Boutegrabet L, Gougeon RD, Schmitt-Kopplin P (2014) A grape and wine chemodiversity comparison of different appellations in Burgundy: Vintage vs terroir effects. Food Chem 152:100 107. doi:10.1016/j.foodchem.2013.11.056

Sadras VO, Soar CJ (2009) Shiraz vines maintain yield in response to a $2-$ $4{ }^{\circ} \mathrm{C}$ increase in maximum temperature using an open-top heating system at key phenostages. Eur J Agron 31:250-258. doi:10.1016/j. eja.2009.09.004

Serrano-Lourido D, Saurina J, Hernández-Cassou S, Checa A (2012) Classification and characterisation of Spanish red wines according to their appellation of origin based on chromatographic profiles and chemometric data analysis. Food Chem 135:1425-1431. doi:10. 1016/j.foodchem.2012.06.010

Soufleros EH, Bouloumpasi E, Tsarchopoulos C, Biliaderis CG (2003) Primary amino acid profiles of Greek white wines and their use in classification according to variety, origin and vintage. Food Chem 80:261-273. doi:10.1016/S0308-8146(02)00271-6

Sáenz C, Cedrón T, Cabredo S (2010) Classification of wines from five Spanish origin denominations by aromatic compound analysis. J AOAC Int 93:1916-1922

Van Leeuwen C, Friant P, Choné X, Tregoat O, Koundouras S, Dubourdieu D (2004) Influence of climate, soil, and cultivar on terroir. Am aJ Enol Viticult 55:207-217

Yau I-H, Davenport JR, Rupp RA (2013) Characterizing inland Pacific Northwest American viticultural areas with geospatial data. Plos One 8(4):e61994v. doi:10.1371/journal.pone.0061994 